\title{
LA BIOGRAFÍA LITERARIA EN EL CONTEXTO HISTÓRICO-CULTURAL (LA CORRELACIÓN TIPOLÓGICA ENTRE EL TEXTO Y LA PERSONALIDAD DEL AUTOR)*
}

\author{
Iuri M. Lotman \\ (Traducción del ruso de Rafael Guzmán)
}

El concepto de biografía del escritor, al igual que otros conceptos similares por el tipo de noción que representan (propiedad del autor, propiedad literaria, etc.), no han existido siempre, sino que tienen una concreción histórica y biográfica. Aparece en determinadas condiciones y solamente en su contexto puede tener una realización concreta.

Las razones que condujeron en la historia de la cultura europea a la brusca actualización de la categoría de la personalidad del autor y, consecuentemente, al agravamiento del problema de la biografía son muy bien conocidas. Esto permite proponer el aspecto tipológico del problema.

* «Literaturnaia biografia $\mathrm{v}$ istoriko-kulturom kontekste ( $\mathrm{k}$ tipologicheskomu sootnosheniu teksta i lichnosti avtora)», Izbrannye stati $v$ trioj tomaj, Tallinn, Aleksandra Publishers, 1992, tomo I, págs. 365-376. 
La premisa natural del acto informativo consiste en que los conceptos de texto y del que crea este texto son conceptos separados. Además, es precisamente el primero (una comunicación sobre un cierto acontecimiento) el que interesa al oyente. A esta situación le corresponde una serie de nociones. No todas las personas que viven en una sociedad tienen derecho a la biografía. Cada tipo de cultura elabora sus modelos de «personas sin biografía» y «personas con biografía». Aquí es evidente la relación con el hecho de que cada cultura crea, en su modelo ideal, un tipo de persona cuya conducta está predeterminada plenamente por un sistema de códigos culturales y otro tipo de persona que posee una determinada libertad de elección de su propio modelo de conducta.

¿Cómo se determinan los conceptos de «persona con biografía» y «persona sin biografía»? Cada tipo de relación social forma un determinado conjunto de funciones sociales, que se muestra a los miembros de dicha sociedad tan forzadamente como la lengua materna, y toda la estructura de la semiótica social existente antes del nacimiento de un individuo determinado o que le es presentado como «condición del juego». En unas condiciones, este papel está predeterminado de forma fatal; a veces, incluso, antes del nacimiento del individuo (por ejemplo, en las sociedades de castas o de sucesión gremial), en otras, el hombre tiene libertad de elección en los límites de un cierto número establecido de posibilidades. Sin embargo, una vez hecha esta elección inicial, el hombre se encuentra en los límites de una cierta norma de conducta «correcta» fijada socialmente. En este caso, la biografía de una persona, desde el punto de vista moderno, no es su biografía, sino que representa solamente un código de reglas generales de comportamiento, idealmente personificadas en las conductas de una persona determinada. Es natural que contrapongamos tal biografía a las biografías en nuestro significado habitual. En estos casos, se suele hablar de ausencia o de falta de desarrollo en una determinada sociedad del sentimiento de la personalidad, como si aún no se hubiera distinguido de una especie de colectivo «impersonal».

Sin embargo, se puede mirar esta cuestión también desde otro lado. Pese a todas las diferencias existentes entre la biografía ideal del santo medieval, compuesta de un conjunto de tópicos, y la biografía moderna, que describe los rasgos personales e irrepetibles de la persona, entre ellos existe algo común: de la multitud de personas, cuya vida y acciones no se convierten en objeto de descripción y no se introducen en la memoria colectiva, se elige a alguien cuyo nombre y modo de actuar son conservados para los descendientes. Los primeros, desde el 
punto de vista de los textos de su época, parece como si no existieran, mientras que a los segundos se les otorga existencia. En el código de la memoria se introducen únicamente estos últimos. Desde este punto de vista solamente los segundos «tienen biografía».

¿Pero qué es lo que puede unir a tipos tan diferentes de conducta como, por ejemplo, el medieval, orientado hacia el cumplimiento ideal de la norma y, por decirlo así, a su disolución en ella, y el tipo romántico que se afana por una originalidad máxima y por una desviación de cualquier norma? Tienen algo en común: en ambos casos, el hombre realiza no una norma rutinaria, media, de conducta habitual para cada tiempo y para cada contexto social, sino una norma difícil, inusual, «extraña» para otros, y que exige de él unos esfuerzos enormes. De esta forma, resulta invariante la antítesis entre la conducta «habitual», impuesta a una determinada persona como una norma obligatoria para todos, y la conducta «inusual», que viola esta norma en aras de cualquier otra norma libremente elegida (cualquier intento de seguir una conducta no normalizada resulta ser, en realidad, la elección de una norma particular admitida como excepción por dicho código cultural). Así, por ejemplo, la conducta del santo medieval, desde el punto de vista del investigador de la literatura biográfica, es trivial y está compuesta de episodios previsibles. Sin embargo, desde la posición del contemporáneo, puede calificarse como «extraña». Esto siempre es una hazaña, es decir, un exceso cuya realización exige una fuerza de voluntad, la superación de una resistencia. La hagiografía es algo estereotipado, pero la conducta del santo es individual. La conducta santa de Teodosio Pecherski es percibida por su madre seglar como incorrecta y vergonzosa: «Has traído la vergüenza para ti mismo y para toda tu estirpe». La madre quiere obligar a Teodosio al cumplimiento de la norma de conducta y «muchas veces por su gran ira se enfadaba y le golpeaba, era fuerte y robusta como un hombre» ${ }^{1}$. El alejamiento de la norma rutinaria exige un esfuerzo de voluntad: «la palabra digna y la acción hecha por amor a Dios, y la fuerza libre están dirigidas a Dios» ${ }^{2}$. Allí donde para la persona de norma rutinaria no existe elección y, consecuentemente, no hay una conducta, para la «persona con biografía» surge la elección que exige una acción, una conducta. Desde el punto de vista romántico, el esfuerzo de voluntad, la tensión de los actos es necesaria para adjudicar a la persona una conducta individual. Desde una posición medieval, lo aparente y lo perecedero es diverso,

D. Abramovich, Kievo-Pecherski paterik. Kiev, 1931. V. 5, pág. 24.

2 Pamiatniki literatury Drevnej Rusi. XII. Moscú, 1980, pág. 408. 
lo eterno y lo auténtico es único. Se requieren esfuerzos muy grandes para acercarse a los modelos eternos de la conducta. Pero en ambos casos se trata de esfuerzos, de la elección de una conducta allí donde, desde el punto de vista de la norma general, no existe elección.

Precisamente esto distingue al hombre y lo hace «portador de una biografía». Así, Francisco de Asís subrayaba que la verdadera esencia del hombre consiste no en lo que él recibe, sino en lo que él adquiere como resultado de su elección libre. «...No podemos enorgullecernos de ninguno de los dones divinos; pues no nos pertenecen (la cursiva es mía. I. L.) sino a Dios [...]. ¿Por qué entonces te enorgulleces de esto, como si tú mismo lo hubieras creado? Pero estamos en el derecho de enorgullecernos de nuestros tormentos y aflicciones de la cruz porque son nuestros propios» ${ }^{3}$, es decir, son elegidos voluntariamente aunque hubo la posibilidad de evitarlo.

Así aparecen los papeles culturales del simple y del bandolero, del santo y del héroe, del brujo, del loco, del goliardo, del proletario, del bohemio, del gitano y de muchos otros que han recibido una norma especial y el derecho a una conducta exclusiva (o anticonducta). Cada uno de estos personajes, y otros similares a ellos, pueden ser valorados, dependiendo de la orientación de los códigos culturales, de forma positiva o negativa, pero todos ellos reciben el derecho a la biografía, el derecho a que su vida, su nombre, sean inscritos en la memoria de la cultura como excesos del bien o del mal.

La memoria cultural está organizada de dos maneras: fija las reglas (las estructuras) y las violaciones de las reglas (los acontecimientos). Las primeras son abstractas como normas. Las segundas, concretas y tienen nombres de personas. Esta es la diferencia entre la prescripción de la ley y los renglones de la crónica. De esta última nace la biografía. Sin embargo, para que nazca entre «el que tiene una biografía» y el que no la tiene pero que la a va a leer, debe aparecer aún otra persona: el que la escribirá.

En las culturas arcaicas y en las culturas medievales, el que escribe la biografía no la tiene él mismo. Sin embargo, a menudo, tiene nombre, sobre cuyo recuerdo se incluye información en los textos. Esto lo diferencia de la «masa que no tiene biografía». Su situación es intermedia.

3 «"Tsvetochkai" Frantsiska Assizskogo» // S Kazania obedniake Jristove: (Kniga o Frantsiske Assizskom). Moscú, 1911, pág. 43. 
La exclusividad, que da derecho a una inclusión personal en la memoria del colectivo, puede ser diferente tanto cuantitativa como cualitativamente. Desde el punto de vista cuantitativo puede consistir en un cumplimiento sumamente preciso de la norma, que, por sí sola, no supone nada exclusivo en dicha sociedad. "Ser caballero» es una cualidad común de un estamento, pero ser un «caballero irreprochable» es una cualidad exclusiva. Esta es la misma diferencia que existe entre el príncipe y el príncipe ideal. En determinadas situaciones, un simple cumplimiento de las normas estándar ya se percibe como una exclusividad (compárese la comedia de N.R. Sudovshchikov, El prodigio inaudito o el Secretario Honrado, 1790). En estos casos, la exclusividad reside no en la naturaleza de la norma sino en el hecho de su realización.

La jerarquía cualitativa la forman las normas con una limitación progresiva del círculo de personas a las que se extiende, que llega incluso a normas individuales, únicas, válidas solamente para una determinada personalidad. Esta conducta para el observador externo se lee fácilmente como conducta «sin reglas». El delincuente, el bogatyr ${ }^{4}$, el simple, el profeta, ocupan diferentes escalones en esta escalera, que forman el rasgo tipológico característico de una determinada cultura. Aquí no solamente el cumplimiento de la norma, sino también su misma elección o incluso la actividad creativa individual en este campo, se convierte en un rasgo determinante de la conducta.

Así de jerárquica es también la posición del creador de la narración biográfica. Forma la escala que va desde la inspiración divina hasta la encomienda administrativa. La base de la jerarquía será aquí el tipo de licencia para tener el derecho de ocupar este puesto, colocado en el código socio-semiótico de la cultura. No es casual que un lugar común de la literatura hagiográfica sea la duda del hagiógrafo sobre su derecho a llevar a cabo esta actividad y su invocación de ayuda a las fuerzas sagradas.

La necesidad de conservar la biografía del que, en un determinado sistema, ocupó un lugar de «persona con biografía» es un imperativo cultural, conduce al nacimiento de una serie de casos mitológicos, anecdóticos y pseudobiográficos. Pero crea chismes y una demanda de literatura memorialística.

4 Héroe de la epopeya rusa. Nota del traductor. 
En este sentido, es especialmente característica la facilidad con la que textos épicos, novelísticos, cinematográficos, etc. de este tipo son propensos a adquirir un carácter cíclico, a unirse en una cuasi biografía y a convertirse en una realidad biográfica para el público. Es conocida con qué insistencia la conciencia del lector dota a personajes como Sherlock Holmes de «biografías» desgajadas del texto. Es igualmente significativo el proceso de creación de biografías mitológicas de las estrellas del cine, autónomas tanto en relación con textos cinematográficos aislados como con las biografías reales de los artistas, y que son un modelo que irrumpe activamente tanto en cualquier texto cinematográfico nuevo como en la propia vida del artista. El ejemplo de Marilyn Monroe es muy significativo en este sentido.

Cuanto más activamente se muestre la biografía de aquel a quien está dedicado el texto menos posibilidades de «tener biografía» tendrá el creador de ese texto. En este sentido, no es casual que la biografía del autor se convierta en un hecho cultural consciente, especialmente en aquellas épocas en que el concepto de creación se identifica con el de la lírica. En este período la leyenda cuasi biográfica pasa al polo del narrador y de forma activa expresa sus pretensiones de sustituir la biografía real. Esta ley de complementariedad entre la trama de la narración y la capacidad de mitologización de la biografía real del creador del texto puede ser ilustrada con muchos ejemplos, desde Petrarca a Byron y a Zhukovski.

El hecho de que la "persona sin biografía» crea un texto sobre una "persona con biografía» está relacionado con la idea de la desigualdad de su estado cultural.

El código cultural que traslada el centro de la atención al narrador, y a fin de cuentas que conduce a la aparición de su biografía, está relacionado con la complicación de la situación semiótica.

En el estado descrito más arriba tácitamente se suponía que el creador del texto está privado de alternativas de comportamiento y que está condenado a la creación de textos exclusivamente auténticos. La inspiración divina del evangelista o la experiencia vital del autor de la biografía de Alexander Nevski («fue testigo de su edad») y la competencia tácitamente sobreentendida de Plutarco obligaban a percibir sus obras como indudablemente auténticas. La autenticidad se presupone. Sólo tiene derecho a crear textos aquel cuya creación, desde ese punto de vista, no puede ser puesta en duda; es más, el concepto de autenticidad está incluido en el concepto de texto. El texto como fenómeno de la cultura se diferencia de toda la masa de mensajes que no son textos 
en que le es inherente, desde los tiempos más remotos, la autenticidad. Al igual que el público del cantor épico no puede poner en duda la autenticidad de sus mensajes, así el mismo cargo de historiógrafo cortesano o de autor de odas hace innecesaria la comprobación de los textos creados por él en el marco de una cultura determinada. Si este tipo de textos difiere de la realidad vital, evidente y conocida por el público, entonces se pone en duda no él sino la propia realidad hasta el punto de declararla inexistente.

Puesto que la autenticidad no se determina por los méritos de un determinado «hablante», que no crea el mensaje, simplemente lo «difunde», sino que a priori se atribuye al texto (según el principio de: «lo labrado en piedra, lo grabado en cobre o lo escrito en pergamino, o pronunciado desde el ambón, o lo escrito en verso o dicho en una lengua sagrada, etc., no puede ser mentira»), entonces es la presencia de estos rasgos y no la personalidad del hablante la que asegura la credibilidad del mensaje. En este sentido, son características las afirmaciones de los libreros rusos antiguos, recogidas por B. A. Uspenski, acerca de que la escritura de un texto en eslavo eclesiástico ya es una garantía de su autenticidad: «El eslavo eclesiástico aparece, ante todo, como un medio de expresión de la verdad divina, está relacionado con el principio sagrado Divino. Así se entienden las declaraciones de los libreros rusos antiguos que afirmaban que en esa lengua es imposible la mentira. Así, en palabras de Ioann Visenski, "en la lengua eslava no puede tener lugar ni la mentira, ni el encanto diabólico"»5.

Simultáneamente, la ausencia del interés biográfico por el creador del texto se determina también por el hecho de que él se percibe de forma fantástica no como autor, sino solamente como un intermediario que recibe el Texto de unas fuerzas superiores y que lo transmite al público. Su papel es un papel auxiliar.

Al complicarse la situación semiótica, el creador del texto deja de tener una función pasiva y privada de la propia conducta del portador de la verdad, es decir, adquiere, en el pleno sentido de la palabra, el estado de creador. Recibe la libertad de elección, se le empieza a con-

5 Uspenski B. A. Yazykovaia situatsia Kievskoj Rusi i ieio znachenie dlia istorii russkogo literaturnogo yazyka. Moscú, 1983, págs. 51-52. Los rasgos del texto son imprescindibles para el público, que por ellos reconoce su superior autoridad. Sin embargo, esta misma autoridad no depende de los rasgos, sino que se da a priori. Al igual que la existencia de monedas falsas no niega sino que confirma la autoridad de las auténticas, la existencia de libros repudiados o de parodias (en una etapa posterior) no niega la santidad de los libros sagrados. Cualquier texto se encuentra en el campo de muchas leyes, que determinan la inevitabilidad de sus diversas interpretaciones. 
ceder un papel activo. Esto, por un lado, conduce a que le sean aplicables las categorías del proyecto, de la estrategia de su realización, de la motivación de la elección, etc., es decir, recibe una conducta, y esta conducta se valora como exclusiva. Por otro lado, el texto creado por él ya no puede verse como auténtico desde su origen: la posibilidad de error o de una mentira directa aparece simultáneamente con la libertad de elección.

Estas dos condiciones son impulsos para que el autor reciba el derecho a la biografía. En primer lugar, la propia creación del texto se convierte en acción de una actividad personal y, consecuentemente, conduce al autor a esa categoría de personalidades desgajadas de los códigos universales, a las que les es propio tener biografía. En segundo lugar, las obras creadas por él ya no pueden provocar en el público una fe automática, y el criterio de autenticidad del mensaje adquiere un carácter exclusivamente agudo y actual. Si antes la autenticidad se garantizaba mediante el estado cultural del creador del texto, ahora la fe en él depende de su personalidad. La honradez personal del autor se convierte en criterio de autenticidad de su mensaje. La biografía del autor se convierte en constante compañero de viaje de sus obras, implícita o explícitamente.

En la literatura rusa, en la que la tradición de la veracidad del texto y del abiografismo del autor (el arcipreste Avvakum es una clara excepción que tan sólo confirma la regla general) se mantuvo durante mucho tiempo llegando hasta principios del siglo XVIII, el problema de la biografía del escritor se planteó naturalmente con una agudeza especial. Esto se subrayaba también por el hecho de que la percepción del arte como valoración en sí mismo, la tradición del principio lúdico, combinatorio-sintagmático, apenas se desarrolló en la literatura rusa. La orientación hacia la semántica, la idea de que las tareas propiamente artísticas estaban llamadas a servir a las tareas religiosas, estatales o de otro tipo, plantearon, de forma extremadamente aguda, el problema de la veracidad del texto y del derecho de un determinado hombre a actuar como creador de textos.

Los investigadores de la literatura rusa del siglo Xvin se ocuparon con frecuencia de las polémicas surgidas entre Trediakovski, Lomonosov, Sumarokov y sus partidarios. El carácter extremadamente personal de estas discusiones, la abundancia de ofensas personales y el constante paso de los autores del análisis de cuestiones literarias fundamentales a la crítica de los caracteres y de las cualidades morales de sus oponentes, se explica con frecuencia por el «insuficiente desarro- 
llo» de su conciencia literaria y por la incapacidad de elevarse hasta discusiones puramente teóricas. La esencia del problema reside, al parecer, en otra cosa. La cuestión es si un determinado autor tiene derecho a ser autor. Los ataques a las cualidades morales del escritor (la acusación contra Lomonosov de ser un borracho, contra Trediakovski de ser un hipócrita y un estúpido, contra Sumarokov de tener malos modos y una apariencia desagradable, las insinuaciones sobre las circunstancias familiares de Elaguin, etc.) deben demostrar que sus obras no pueden aspirar a la autenticidad y percibirse con confianza. La discusión literaria plantea el problema de la biografía del autor. Es significativo que este problema nunca se planteó con Feofan Prokopovich, pese al carácter dudoso de su conducta personal. Le pudieron acusar de delitos, pero su derecho a ser creador de textos se basó en una prerrogativa estatal y en un rango eclesiástico, que estaba separado de su personalidad al igual que el rango eclesiástico lo estaba de su indigno y casual portador. Del mismo modo que en la biografía personal del sacerdote desempeña tan sólo una función subordinada en el ritual de la ceremonia religiosa que él realiza, la biografía personal de Prokopovich parece como si se olvidara en el momento de su servicio al Estado. Lomonosov también hablaba en nombre del Estado, pero no fue ni propuesto, ni llamado, ni consagrado; él mismo llegó a este puesto y su derecho a desempeñar esa función podía ser contestado y, de hecho, lo fue en muchas ocasiones.

San Pedro Derzhavin incluso podía pensar que su verdadera biografía era la biografía de hombre de Estado:

El escritor de sátiras me atormenta por mis palabras y me respeta por mis acciones.

La particularidad de su posición como escritor la veía en el hecho de que siendo cantor de Felitsa era simultáneamente cantor de sí mismo. Creador de la apoteosis biográfica de la monarquía humana, fue simultáneamente el biógrafo poético del alto dignatario, del sabio y del poeta Gabrila Derzhavin. La innovación de Derzhavin repite de forma sorprendente la de Avvakum. En ambos casos, el vino nuevo se vierte en pellejos viejos.

Sin embargo, Radischev ya debió «añadir» a su obra la biografía de un héroe antiguo. Los ejemplos de Catón y de Gilbert Romme le pusieron en su mano una navaja de afeitar. Precisamente, la ausencia 
de razones concretas para el suicidio hacían de este paso, premeditado desde hace tiempo, no un episodio de su realidad extrabiográfica (parecido a los fracasos trágicos en las vidas de Trediakovski y de Sumarokov), sino un hecho de alta Biografía. Su disponibilidad para la muerte garantizaba la autenticidad de sus obras.

De esta forma, a principios del siglo XIX, en la cultura rusa se confirma la idea de que precisamente el poeta tiene derecho, en primer lugar, a la biografía. Un rasgo particular pero característico fue la costumbre consolidada de adjuntar a las obras los retratos de los autores. Antes esto se hacía únicamente para los que habían muerto o para los que, en vida, eran reconocidos como escritores clásicos. Y si antes en el retrato se subrayaban los signos de los poderes estatales o de otro tipo (por ejemplo, la corona de laurel, el dedo señalando al busto del señor cantado por el poeta, los libros del poeta (la erudición), sus medallas (los méritos), etc.), ahora al lector le proponen mirar atentamente a la cara, como si, al recibir una importante información de esa persona desconocida, miráramos atentamente los rasgos de su cara y su mímica, buscando razones para la confianza o la desconfianza.

Los escritores de principios del siglo XIX no solamente viven, sino que se crean una biografía. La teoría del romanticismo y el ejemplo de Byron resultan aquí impulsos paralelos excepcionalmente favorables.

La diferencia entre la vida «extrabiográfica» y la biográfica consiste en que la segunda permite la causalidad de los acontecimientos reales a través de códigos culturales de la época (las biografías de grandes pesonajes, los textos artísticos -especialmente en esta época los teatrales- y otros modelos ideológicos). Además, los códigos culturales no solamente seleccionan los hechos relevantes de toda una masa de conductas vitales, sino que se convierten en un programa de una futura conducta que lo va acercando de forma activa a la norma ideal.

Especialmente remarcable en este sentido es el ejemplo de Pushkin, para quien la creación de su propia biografía fue objeto constante de sus esfuerzos, como lo fue su creación artística.

Al mismo tiempo, no podemos olvidar en qué medida cambió el estado literario de Ryleev después de su ejecución en la fortaleza de Pedro y Pablo. Para la generación de principios de 1820, para los contemporáneos de Pushkin, para los lectores del tipo de Delvig, Ryleev era un poeta secundario (cuyo talento era más que dudoso, aunque su obra fuera conocida en toda su extensión por ellos). Para la generación de Lermontov y de Guertsen, Ryleev está junto a Pushkin y a Griboedov, como uno de los primeros poetas rusos. 
Crece fuertemente la mitologización biográfica. En este sentido, es típico el destino literario del poeta ruso más «sin biografía» de aquella época, I. A. Krylov. En torno a su nombre aparece toda una nube de leyendas biográficas, que constituye una mitología original. Es característico también el proceso de mitologización de la personalidad de Pushkin (testimonio de la transformación del poeta en «personaje histórico»), que se mantiene hasta nuestro tiempo y que es un elemento activo no solamente de la literatura de memorias, sino también de la literatura cuasi científica sobre el poeta.

Un testimonio brillante del crecimiento de la significación cultural de la biografía del escritor es la aparición de las pseudobiografías. La creación de la personalidad del escritor se convierte en una variedad de literatura (Kozma Prutkov). En el siglo XVIII existían poetas sin biografía. Ahora aparecen biografías sin poetas. Simultáneamente, la personalidad del portador del texto se convierte en objeto de investigación artística. Aparece así el problema del narrador.

La aparición del libro de P. L. Yakovlev, El manuscrito del difunto Klementi Akimovich Jabarov, que contiene el razonamiento sobre el alfabeto ruso y su biografía escrita por él mismo y con un retrato y la reproducción de la caligrafía de este ilustre hombre (Moscú, 1828), con la siguiente indicación: «Publica Evgueni Treteiski, librero ambulante», lo que se convirtió en una completa mixtificación: la biografía, el retrato, el facsímil de la letra, testimoniaban la realidad del autor que nunca existió. La aparición de las obras de Jabarov coincidió no de forma casual con el nacimiento de personajes literarios tales como Iván Petrovich Belkin, Rudy Panko, Irinei Modestovich Homozeika o Porfiri Baiski ${ }^{6}$.

Precisamente porque la biografía del escritor se percibe no como algo dado tan automáticamente como su existencia biológica, es posible una biografía ficticia o la pretensión de tener una biografía en casos de su ausencia real. Este último caso fue demostrado por Pushkin con el ejemplo de Iván Petrovich Belkin en la Historia de la aldea de Goriujin. De la misma forma que Goriujin no tiene historia, tampoco Belkin tiene biografía. La exposición del autor, convertida en pseudobiografía, pseudohistoria de Goriujin, crea la distancia entre el texto y su verdadero autor, Pushkin, por un lado, y el lector por otro.

6 Como testimonio de la autenticidad de los datos biográficos y de la realidad de las personas inventadas actúan las indicaciones del lugar donde se conservan los manuscritos y los nombres de los editores. A(lexandr) P(ushkin), maestro de filosofía, miembro de diferentes sociedades científicas V. Bezglasny, etc. 
Mientras la licencia para ser autor se daba como una especie de función socio-cultural indiscutible, la cuestión sobre la correspondencia entre las posibilidades del creador del texto y el tema que le era prescrito no podía surgir. El que no tenía plenos poderes fijados en el código de la cultura (que podía ser la inspiración divina, una prueba, la victoria en una competición, el reconocimiento de los entendidos, etc., pero siempre precediendo al derecho a la creación) producía solamente «no-textos» $y$, desde el punto de vista de dicha cultura, simplemente no existía. Ahora el derecho a ser autor se daba como autodeterminación y eran posibles los casos de un grado diferente de correspondencia/no correspondencia entre el autor y el objeto descrito.

Pushkin, en 1830, desarrolló este tema de forma minuciosa, creando toda una serie de imágenes portadoras de una conciencia ingenua, que describían una situación cuyo sentido profundo les era inalcanzable.

De esta forma, hacia los años 1830-1840, en Rusia se creó una situación muy interesante. En primer lugar, la importancia social del arte presuponía en el escritor «una persona con biografía». En segundo lugar, «tener una biografía» significaba no solamente la presencia de determinados rasgos sígnicos por los cuales se reconocía una especie de código cultural de la personalidad (por ejemplo, los rasgos de «palidez», «taciturnidad», «mirada ardiente o apagada», «amor disimulado», «pasado enigmático», «muerte temprana» o "enfermedad mortal», ejemplificaban al héroe romántico; determinados rasgos podían leerse como una tarjeta de visita de «Mefistófeles», «Melmot», «vampiro», etc.). Ahora ya no es suficiente ser reconocido como

\author{
Melmot, \\ cosmopolita, patriota, \\ Harold, cuáquero, hipócrita \\ o llevar puesta otra máscara
}

o tener en el alma «maldades, por lo menos tres», para que la sociedad te codifique como «persona con biografía». La biografía se convierte en un concepto más complejo que la máscara elegida conscientemente. Supone la presencia de una historia interna. Pero, por cuanto la historia se reconoce en este período como un movimiento de la inconsciencia a la conciencia, la biografía es un acto de autoeducación gradual dirigida a la claridad intelectual y espiritual. Tan sólo la «búsqueda de la verdad» da un pleno poder socio-cultural para crear obras que en el contexto de una determinada cultura pueden percibirse como sus textos. 
Es esencial prestar atención a una circunstancia, característica precisamente de la cultura rusa: el derecho del escritor a la biografía y, respectivamente, el interés del lector por la vida del creador del texto y por su biografía surge mucho antes que estas mismas categorías cuando se trata de pintores, compositores o artistas. Según esto, se distinguía también el prestigio social de estas profesiones. La poesía, hasta que se convirtió en profesión, fue en el siglo XVIII compatible con un servicio estatal elevado, y cuando se convirtió en tarea profesional en torno a 1830 no afectó al estado social del autor, mientras que la escena y el pincel dejaron al autor en una situación humillante. Es conocido que la familia de F. Tolstoi (ipresidente de la Academia de Bellas Artes!) consideraba su fidelidad a la pintura profesional como una humillación para la familia. Este fenómeno tiene explicación.

En la Rusia de antes de Pedro el Grande, la literatura eclesiástica no era «un arte entre otros», sino que representaba la capa más alta de la creación de textos en un sentido axiológico. Esto está relacionado también con la idea de los textos sagrados como inspirados por Dios y con el especial papel de la palabra en la conciencia cultural de la Edad Media rusa. El que escribía la vida del santo era también partícipe de esa santidad.

En la cultura posterior a Pedro el Grande, lo eclesiástico fue sustituido funcionalmente por lo estatal. La poesía, como asunto estatal, heredó un prestigio cultural superior. Pero el poeta, como persona perteneciente al Estado, expresó su derecho a la biografía. La participación de la santidad fue sustituida por la participación de la verdad. Pero esta última exigía garantías extratextuales que nadie exigía del artista o del pintor.

Las normas de la biografía del escritor se fueron formando de modo gradual. En el siglo XVIII el primer paso de la introducción de la biografía del escritor en la cultura consistió en su igualación con el funcionario. En este sentido, la inclinación de las primeras biografías de los escritores en Rusia hacia los estereotipos del escalafón no fue un defecto ni un resultado de la «inmadurez» de sus autores, sino que surgía de una posición consciente. Sin embargo, existía también la tendencia opuesta, que se expresaba en la creación de ciclos alrededor de los nombres de escritores famosos de cuentos anecdóticos, que constituían un mito biográfico completo. La biografía del escritor es el resultado de la lucha entre el escalafón y la anécdota. Pushkin va a coleccionar anécdotas de la vida de Sumarokov, Barkov, Kostrov, Gnedich, 
Milonov, pero según su camino vital propondrá un principio totalmente distinto: la biografía como acto creador ${ }^{7}$.

En los años 1830-1840, el tipo de biografía del escritor se convertirá en un campo no sólo de reflexiones y de esfuerzos conscientes, sino también de experimentación. Simultáneamente, aparecían también estereotipos negativos. Así, por ejemplo, F. Bulgarin, que fue un escritor destacado y bastante popular en su tiempo, que poseía un indudable talento de periodista, entró en la literatura precisamente por su biografía oscura. La cuestión de la independencia personal, de la integridad de opiniones testificadas por hechos de la biografía, se convirtió en criterio de confianza para el lector. En este sentido, la persecución, el exilio o el servicio militar, que podían amenazar al escritor en un sentido muy distinto al estereotipo de la biografía romántica, se convertían en objeto especial de atención. Compárese el retrato de Bestuzhev-Marlinski en Cien literatos rusos y de Polezhaev en la publicación de sus Versos (1857): el retrato de Bestuzhev con su burka ${ }^{8}$ aludía a su exilio en el Cáucaso, mientras que el capote militar de Polezhaev aludía a su trágico destino. Ambos retratos sustituían una biografía imposible de publicar a causa de la censura.

El derecho del escritor a la biografía, conquistado por Pushkin y percibido por los lectores del primer tercio del siglo XIX, significaba, en primer lugar, el reconocimiento social de la palabra como acto (compárese en este sentido la polémica de Pushkin con Derzhavin) y, en segundo lugar, la idea de que en la literatura lo principal no es la literatura y de que la biografía del escritor en ciertos casos es más importante que su propia creación. La exigencia de ascetismo e incluso de heroísmo en el escritor se daba por supuesta. Precisamente así explicaba Belinski el hecho de que «el título de poeta, la condición de literato, hace ya tiempo que eclipsaron el falso esplendor de las charre-

7 Pero la anécdota sobre Pushkin pasará a la esfera de la cultura de masas y Gogol la pone en boca de Jlestakov como signo característico del medio social: «Pero qué extraño compone Pushkin. Imagínese: ante él hay un vaso lleno de ron, el mejor ron, de unos cien rublos la botella de las que sólo guardan para el emperador austriaco, y después, tan pronto empieza a escribir, la pluma hace solamente: tr..., tr..., tr... No hace mucho tiempo escribió la siguiente obra: una medicina contra el cólera que los pelos se ponen de punta. Un burócrata se volvió loco cuando leyó» (Gogol, N. V. Poln. sobr. soch.: 14 T. Moscú, 1951. T. 4, pág. 294). En la cultura de masas contemporánea, la anécdota lucha activamente por su lugar en la biografía de Pushkin en numerosos «descubrimientos» sensacionales de autores no profesionales sobre el duelo o sobre las pasiones amorosas del poeta.

8 Capote de fieltro que utilizan en el Cáucaso. Nota del traductor. 
teras y las guerreras multicolores», y continuaba: «... aquí el público tiene razón: ve en los escritores rusos a sus únicos jefes» 9 .

Esta idea, por un lado, parece obligar al escritor a realizar en su vida lo que predica en el arte ${ }^{10}, y$, por otro lado, relaciona toda esta serie de problemas con una profunda tradición nacional: distinguir al escritor de toda una masa de artistas, ratificar su derecho a la biografía y la idea de que esta biografía debe ser la vida de un asceta; todo esto estaba relacionado con el hecho de que, en la cultura de la Rusia posterior a Pedro el Grande, el escritor ocupaba el lugar que en la etapa anterior se le concedía al santo, al predicador, al asceta y al mártir. Esta asociación descansaba en la fe en una fuerza especial de la palabra y en su relación íntima con la verdad. Tanto el santo como el escritor debían demostrar, con su ascetismo, su derecho a hablar en nombre de la Verdad Suprema.

El primero en comprender esto - y se horrorizó por ello- fue Gogol. En su artículo El pintor histórico Ivanov, Gogol, protestando contra la opinión que «estaba de moda» (« ¿Es que acaso nos has tomado por tontos? ¿Qué es eso de que hay una relación entre el alma y el cuadro? ¿El alma existe por sí sola y el cuadro existe por sí solo?» ${ }^{11}$ ), aseguraba lo inseparable de la creación y de la formación autodidacta, sin la que el artista «realmente se engañaría a sí mismo y a los demás, pese a su deseo de no hacerlo» ${ }^{12}$. En El Retrato, habiendo puesto en la base de la novela la inseparabilidad de la vida del pintor y de su creación, contrapuso dos imágenes: la del pintor laico, cuyo arte se convirtió en mentira, y la del monje pintor, que encuentra, en su afán por la perfección personal, «todos los grados posibles de paciencia y de esa abnegación inconcebible de la que apenas se pueden encontrar ejemplos en algunas vidas de santos» ${ }^{13}$. De aquí la exigencia planteada en La confesión del autor: «arder de modo evidente con un deseo de perfección ante todos» ${ }^{14}$. Este camino empujaba al escritor a ocupar la posición de predicador y de profeta.

\footnotetext{
9 Belinski V. G. Poln. sobr. soch.: 13 T. Moscú, 1956. T. 1, pág. 217.

10 En este sentido las palabras de Ryleev sobre el poeta tenían un carácter programático:

Santa, alta dignidad del cantor

Está obligado a justificarla con sus hechos.

(Ryleev K. Poln. sobr. stijotvoreni. Leningrado, 1971, pág. 172). Es conocido qué fuente de tormentos espirituales fue para Nekrasov el desacuerdo entre la biografía y la actividad creadora.
}

11 Gogol N. V. Poln. sobr. soch. T. 8, pág. 333.

12 Ibidem.

13 Ibidem. T. 3, pág. 133.

14 Ibidem. T. 8, pág. 444. 
Sin embargo, fue posible también otro camino que podría parecer totalmente opuesto, otro camino hacia la biografía.

En los años 1830-1840, bajo la influencia del éxito de las ciencias naturales, en la literatura orientada hacia el realismo se desarrolló la idea del escritor como un tipo de naturalista, del observador objetivo de los fenómenos sociales y psicólogo-experimentador. En 1831, Baratinsky editó La gitana (La concubina), en cuyo prólogo escribió que en la literatura conviene ver «la ciencia, similar a otras ciencias, buscar en ella la información (la cursiva es de Baratinsky.I. L.)». «Los novelistas, los poetas representan las virtudes y los vicios que ellos notan, los impulsos que regulan las acciones humanas. Buscar en ellas aquello que no tienen los viajeros ni los geógrafos: noticias sobre las cosas que les provocan curiosidad; exíjales lo mismo que a los científicos: la verdad de los testimonios» ${ }^{15}$. Esta exigencia, que había sido la opinión del círculo de Pushkin en 1830, fue valorada por Belinski, en 1842, como «muy inteligente y sensatamente» expuesta. Ideas parecidas expresó Lermontov en el prólogo a su Héroe de nuestro tiempo, comparando al escritor con un médico. Podría parecer que esta opinión empujó a un impasible objetivismo y a quitarle interés a la biografía del escritor. Sin embargo, sucedió lo contrario. El conocimiento de pasiones secretas del ser humano y del laberinto de la vida social exigió del poeta sumergirse en ella. «Observador del corazón de profesión», como definió al escritor ya el mismo Karamzim, debe, personalmente como hombre, pasar a través del mundo del mal para ser capaz de representarlo de modo más real. En la declaración poética Mi futuro en la niebla, Lermontov representó el poeta que había recibido del Creador las copas del bien y del mal. El poeta elige el camino del vicio:

En mi el mal ha luchado contra lo sagrado, he ahogado la voz de lo sagrado,

he vertido lágrimas desde el fondo de mi corazón...

Él comulga con la enfermedad de su generación:

Como un fruto joven, privado de zumo, se secó en las tempestades del destino

bajo el tórrido sol de la vida.

15 Baratynski E. A. Poln. sobr. stijotvoreni: 2 T. Leningrado, 1936. T 2, pág. 176. 
Tan sólo después de esto el poeta es capaz de penetrar en el alma de otras personas:

Entonces estoy preparado para la lid, audazmente penetré en los corazones de las personas a través de enigmáticos velos de las pasiones y conductas mundanas ${ }^{16}$.

En la conciencia de Lermontov el poeta se dibuja con apariencia de profeta. No son casuales los versos incompletos en nombre de Dios:

Meto el fuego en tu boca, daré mi poder a tus palabras ${ }^{17}$.

Sin embargo, para Gogol el don de la profecía se compra con el precio del ascetismo personal, de la marcha del mundo hacia un servicio caballeresco-monacal a la verdad, para Lermontov se compra con una inmersión personal en el mundo que provoca en el autor repugnancia. B. V. Tomashevski mostró de forma convincente la relación de estas ideas con la escuela literaria de Balzac ${ }^{18}$.

Mediante esta orientación se determinaba, por lo visto, la conducta provocativa, característica de Lermontov, que obligaba a las personas a «quitarse los velos de las conductas mundanas». Con esto, al parecer, conviene relacionar los crueles experimentos del episodio con E. A. Sushkova: Lermontov representa en la vida lo que después deberá pasar a la novela. Sin embargo, el paralelo entre el escritor y el científico en el que insisten los literatos de 1840 , se transforma de forma inesperada en una diferencia profunda: el científico-experimentador (esta imagen se relaciona a mitad del siglo pasado ante todo con el naturalista, con el biólogo, con el médico o con el químico) se encuentra fuera del experimento. Lermontov, al realizar en La princesa Ligovskaia los primeros experimentos de costumbrismo, experimenta consigo mismo y con E. A. Sushkova: para describir el vicio, es preciso «ahogar la voz de lo sagrado». La exigencia de convertirse uno mismo en laboratorio de observación de la humanidad, que se remonta a Rousseau, engendró, por un lado, la eclosión de los géneros autobiográficos (Lermontov, Guetzen, L. Tolstoi), y, por otro lado, el afán de

16 Lermontov M. Yu. Soch.: 6 T. Moscú, 1954. T. 2, pág. 230.

17 Ibidem. T. 2, pág. 309.

18 Tomashevski B. «Proza Lermontova i zapadno-evropeiskaia literaturnaia traditsia» // Lit. nasledstvo. Moscú, 1941. T. 43/44. Págs. 502-507. 
experimentar despiadadamente con su propia biografía. Detrás de esto estaba el convencimiento de que solamente «el hombre con biografía» (y ahora pasa a considerarse así aquel que personalmente experimentó las subidas y bajadas del ser humano) tiene derecho a ser creador de biografías ajenas. Una relación semejante con su propia biografía vamos a encontrar más tarde en A. Grigoriev.

Todo este complejo trabajo cultural se completará con la creación de dos grandes biografías: la de Tolstoi y la de Dostoyevski, biografías sin las cuales es impensable la percepción de la obra de estos escritores, ni la cultura del siglo XIX en general.

De esta forma, desde el punto de vista de la tipología, podemos distinguir oposiciones emparejadas: «el que da derecho a tener una biografía-el que recibe el derecho a tener una biografía», «el que tiene una biografía-el que crea la biografía de uno que tiene biografía». Así, en la literatura eclesiástica medieval, la santidad suprema hace santo al portador de una conducta particular, pero ella le da al hagiógrafo, subordinado por lo general a una norma más usual de conducta, el derecho a ser su biógrafo. Las complejas relaciones de estas categorías son características también de otras épocas. Hagamos notar tan sólo que en el sistema del romanticismo todas las funciones tienden a confluir: el que tiene biografía se da derecho a tenerla (es posible también la afirmación contraria: el que se arroga el derecho a la biografía, la tiene) y él mismo la escribe.

La estructura de la red tipológica de la correlación de las funciones y del paradigma de los papeles sociales, con ayuda de los cuales estas funciones se realizan, puede dar una clasificación útil de la tipología de las culturas. 